\title{
Prevention of rat neonatal cardiomyocyte apoptosis induced by simulated in vitro ischemia and reperfusion
}

\author{
Samuil R. Umansky ${ }^{1,2}$, John P. Shapiro', Grace M. Cuenco', \\ Matthew W. Foehr ${ }^{1}$, lan C. Bathurst ${ }^{1}$ and L. David Tomei ${ }^{1}$ \\ 1 LXR Biotechnology Inc., 1401 Marina Way South, Richmond, California, \\ 94804 \\ 2 corresponding author: Samuil R. Umansky. fax: 510412 9109; \\ tel: 510412 9100; email: sumansky@|xr.com
}

Received 4.3.97; revised 30.4.97; accepted 22.5.97

Edited by G. Melino

\begin{abstract}
Apoptosis, or programmed cell death, is an active metabolic response to physiological signals or exposure to cytotoxic agents. Recent evidence has shown that the cell death response can be modified by agents presumed to be unrelated to the initial signal, but capable of interfering with the molecular mechanisms of the apoptotic pathway progression. Here we show the results of investigations on the use of a phospholipid-based pharmaceutical preparation for suppression of myocardial damage. First, we show that serum or serum/glucose deprivation, in vitro ischemia with subsequent simulated reperfusion, inhibition of protein synthesis, and treatment with ceramide, staurosporine, adriamycin, cis-platinum and menadione induce apoptotic death in a primary culture of rat neonatal cardiomyocytes. Then we demonstrate that a mixture of specific phospholipids, which has been originally purified from soy flour on the basis of its antiapoptotic activity, prevents cardiomyocyte death induced by serum or serum/glucose deprivation, by ischemia with subsequent simulated reperfusion, and by ceramide, but not by other cytotoxic treatments. This suggests that ceramide, a lipid secondary messenger which triggers apoptosis induced by some cytotoxic agents, may be involved in the process of signaling ischemia/reperfusion induced apoptotic death of cardiomyocytes. These results further demonstrate that an active pharmaceutical preparation for the suppression of cardiomyocyte death can be formulated based upon a novel strategy of apoptosis modification.
\end{abstract}

Keywords: apoptosis; cardiomyocytes; phospholipids; ceramide; ischemia; reperfusion

Abbreviations: PA, phosphatidic acid; PI, phosphatidylinositol; LPA, lysophosphatidic acid; LPI, lysophosphatidylinositol; LPC, lysophosphatidylcholine; SLF, a lipid fraction purified from soy flour; ROM, reconstituted optimized mixture of phospholipids; DAG, diacylglycerol

\section{Introduction}

The most important consequence of acute myocardial ischemia is the death of individual cells which leads to organ dysfunction. Early reperfusion decreases heart damage but at the same time the massive death of cells that remain viable by the end of ischemia occurs with the restoration of blood flow (Karmazin, 1991; Fox, 1992).

Two forms of cell death, necrosis and apoptosis, have been described and are now intensively and widely investigated (Kerr et al, 1972; Umansky, 1996; Vaux and Strasser, 1996). Necrosis is generally considered to be a result of severe irreversible cell damage. It is characterized by early swelling of the cell and its cytoplasmic organelles with subsequent rupture of the outer membrane. Apoptosis is a much more widespread phenomenon and is an important component of normal development, tissue homeostasis, as well as the pathogenesis of severe diseases. It is usually initiated by specific signals, but also can be induced by mild, non-catastrophic cell injury. Apoptosis is characterized by morphological changes marked by reduction of cell volume and shrinkage of organelles, early chromatin condensation and margination, and membrane blebbing. Specific internucleosomal DNA fragmentation is a hallmark for many, but notably not all, instances of apoptotic death. Several genes and gene families involved in signal transduction and modulation of the apoptotic pathway are already described (Umansky, 1996; Vaux and Strasser, 1996). By definition, necrosis can be prevented only by decreasing cell injury. Whereas, apoptosis is active cell response to a physiological or damaging signal, that can be inhibited by interfering with metabolic processes involved in the apoptotic pathway, without any requirement to prevent cell damage or promote its repair. Prevention of apoptosis by upregulation of bcl-2 and bcl-x expression or by inhibitors of ICE-like proteases are typical examples of this approach to modification of apoptotic cell death (Umansky, 1996; Vaux and Strasser, 1996; Nunez et al, 1994; Whyte, 1996).

Recent data indicate that apoptosis plays a significant role in heart injury induced by ischemia and subsequent reperfusion (Gottlieb et al, 1994; Ito et al, 1995; Umansky et al, 1995, 1996). Severe cell damage during prolonged ischemia appears to result in the necrotic death of myocardial cells. However, if ischemia is relatively limited in extent and duration, the apoptotic pathway is initiated and the restoration of blood flow creates conditions for ongoing apoptosis. IGF and calpain inhibitors, which prevent apoptosis in different systems, also inhibited apoptosis in cardiomyocytes following ischemia and reperfusion both in vivo and in vitro (Umansky et al, 1995; Buerke et al, 1995).

Recently, we have purified from soy flour a lipid fraction (SLF) which is capable of preventing apoptotic death 
induced in $\mathrm{C} 3 \mathrm{H}-10 \mathrm{~T} 1 / 2$ mouse embryonic cells by serum deprivation (Tomei et al, 1993). SFL is a mixture of phospholipids, comprised of phosphatidic acid (PA), phosphatidylinositol (PI), lysophosphatidic acid (LPA), lysophosphatidylinositol (LPI), and lysophosphatidylcholine (LPC). A series of synthetic mixtures of these phospholipids was analyzed in the above mentioned cell system. The highest anti-apoptotic activity was observed with the mixture of PA:PI: LPA: LPI:LPC with the ratio of
$10: 10: 8: 2: 4$, respectively, and referred to as ROM (reconstituted optimized mixture).

Experiments were designed to determine the ability of SFL and ROM to inhibit apoptosis in primary cultures of rat neonatal cardiomyocytes induced by different treatments. The results demonstrated that various treatments, including serum and serum/glucose deprivation, simulated ischemia/ reperfusion, as well as exposure to adriamycin, staurosporine, cis-platinum, and ceramide induce the apoptotic
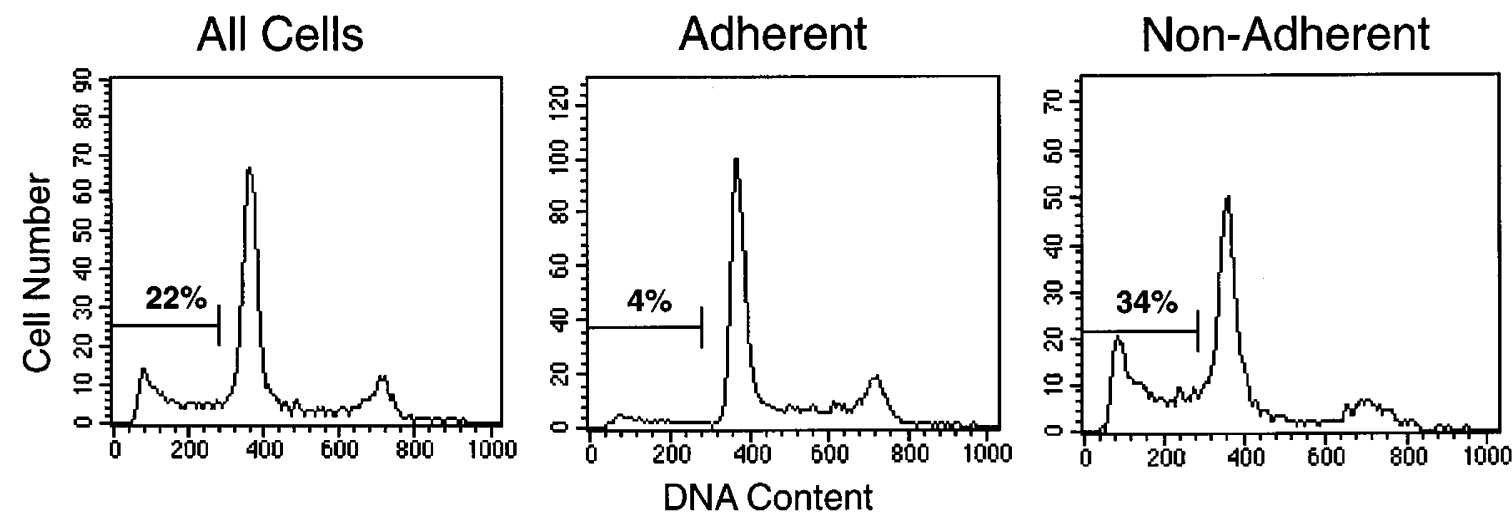

Figure 1 DNA histograms of rat neonatal cardiomyocytes after ischemia and reperfusion. Numbers indicate per cent of $<2 \mathrm{C}$ DNA cells.
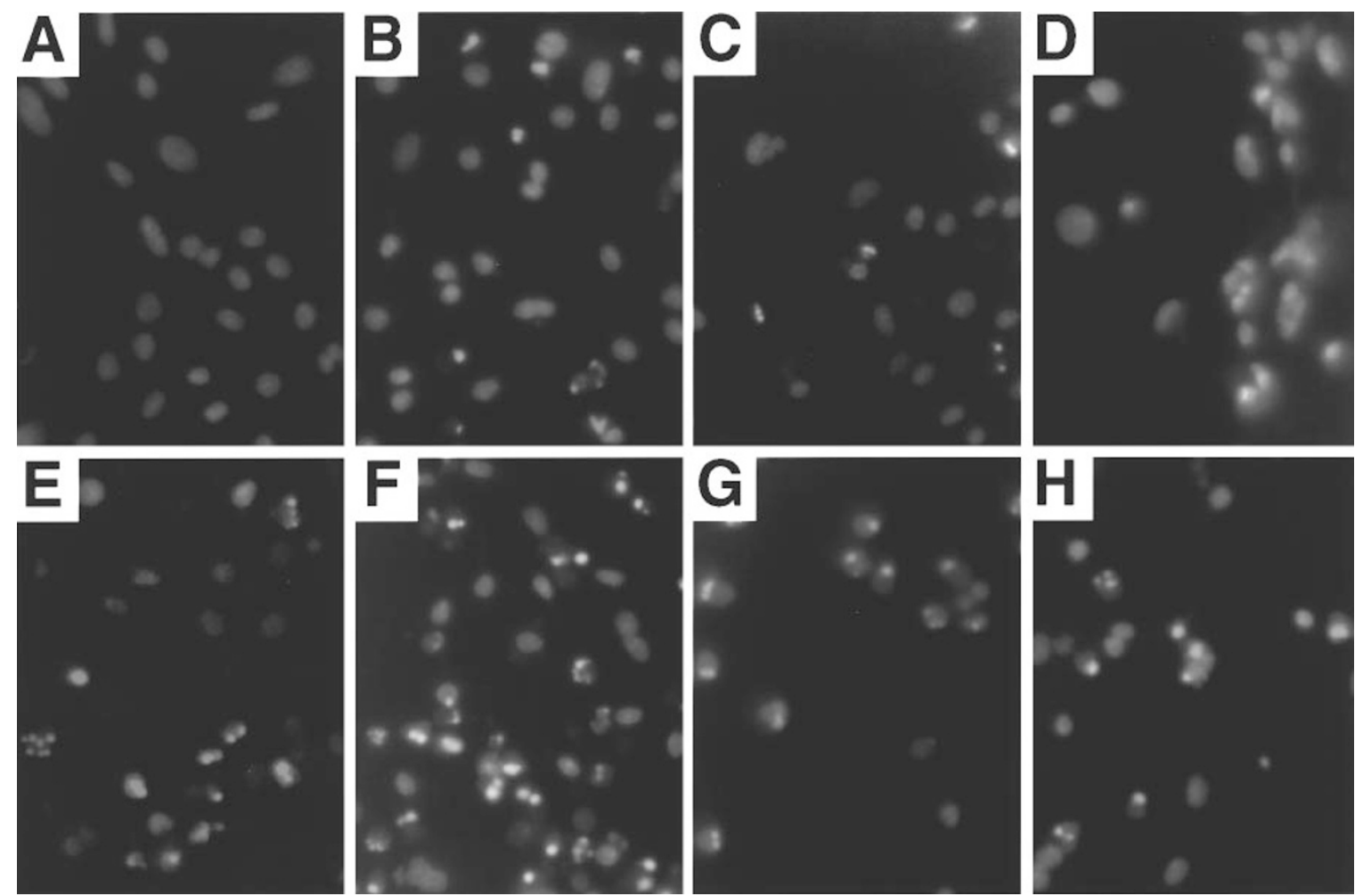

Figure 2 Luminescent microscopy of rat neonatal cardiomyocytes after different treatments. (A) control; (B-H) cells were subjected for $24 \mathrm{~h}$ to serum deprivation (B) or treated with $30 \mathrm{ng} / \mathrm{ml}$ of staurosporine (C), $15 \mu \mathrm{M}$ menadione (D), $75 \mu \mathrm{mol}$ cisplatin (E), $10 \mu \mathrm{g} / \mathrm{ml}$ of cycloheximide (F), $3 \mu \mathrm{g} / \mathrm{ml}$ of puromycin (G) or $12.5 \mu \mathrm{mol}$ C2-ceramide $(\mathbf{H})$. 
death of cardiomyocytes. Both SFL and ROM inhibit apoptosis induced by serum and serum/glucose deprivation, simulated ischemia/reperfusion and ceramide but have no effect on apoptotic cell death initiated by either adriamycin, staurosporine, cis-platinum.

\section{Results}

\section{Cardiomyocyte death induced by ischemia/reperfusion}

Earlier, using morphological criteria, flow cytometry and DNA electrophoresis, we have shown that ischemia (oxygen, serum and glucose deprivation) with subsequent simulated reperfusion (readdition of oxygen, serum and glucose) of rat neonatal cardiomyocytes induces both necrotic and apoptotic cell death (Umansky et al, 1995). DNA degradation is a widely used hallmark of apoptosis and, thus, apoptotic cells can be measured by flow cytometry by determining the proportion of cells that contain less than 2C DNA (Afanasyev et al, 1986, 1993). Figure 1 shows that about $34 \%$ of dead non-adherent cells contain less than $2 \mathrm{C}$ DNA and are presumed to be apoptotic based on this criterion. To model ischemia in these experiments we subjected cells to simultaneous oxygen, serum and glucose deprivation and then restored all these components to simulate reperfusion. Apoptotic cell death was observed predominately during reperfusion (Umansky et al, 1995), which is in accord with data obtained in intact myocardium in vivo (Gottlieb et al, 1994; Umansky et al, 1996). Following $24 \mathrm{~h}$ serum deprivation, approximately $20 \%$ cell death was observed, whereas, $30-40 \%$ cell death was observed in combined serum and glucose deprivation (data not shown). Nuclear morphology (Figure 2B) and internucleosomal DNA fragmentation (Figure 3, lane 1) revealed that cell death was primarily apoptotic. Ischemia with the subsequent reoxygenation but in the continued absence of serum and glucose, resulted in slightly more dead cells than in the presence of a normal glucose level (data not shown). However, the number of apoptotic cells, containing less than 2C DNA, was substantially lower after reoxygenation (Figure 4), suggesting that necrotic cell death was encountered at significantly higher rate in the absence of restored energy production. These results are in a good agreement with in vivo data which indicate that the energy sources, in particular creatine phosphate, are necessary for the apoptotic cell death (Umansky et al, 1996).

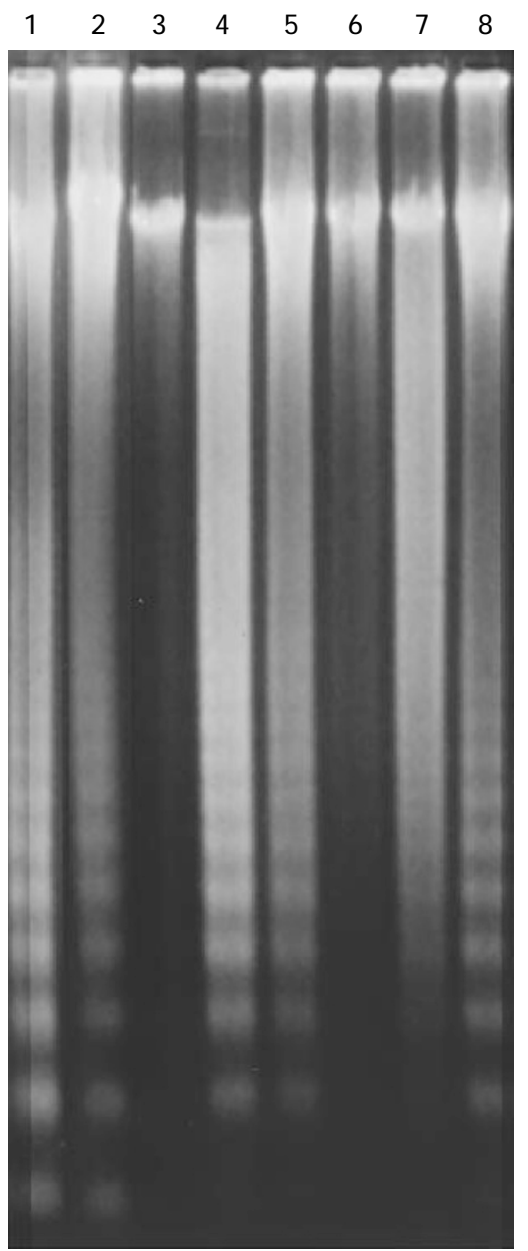

Figure 3 Agarose gel electrophoresis of DNA isolated from rat neonata cardiomyocytes after $24 \mathrm{~h}$ incubation in different conditions. (1) serum and glucose deprivation; (2) $10 \mu \mathrm{mol}$ C2-ceramide; (3) control; (4) $3 \mu \mathrm{g} / \mathrm{ml}$ of puromycin; (5) $10 \mu \mathrm{g} / \mathrm{ml}$ of cycloheximide; (6) $15 \mu \mathrm{mol}$ menadione; (7) $5 \mu \mathrm{g} / \mathrm{ml}$ of adriamycin; (8) $100 \mathrm{ng} / \mathrm{ml}$ of staurospine.
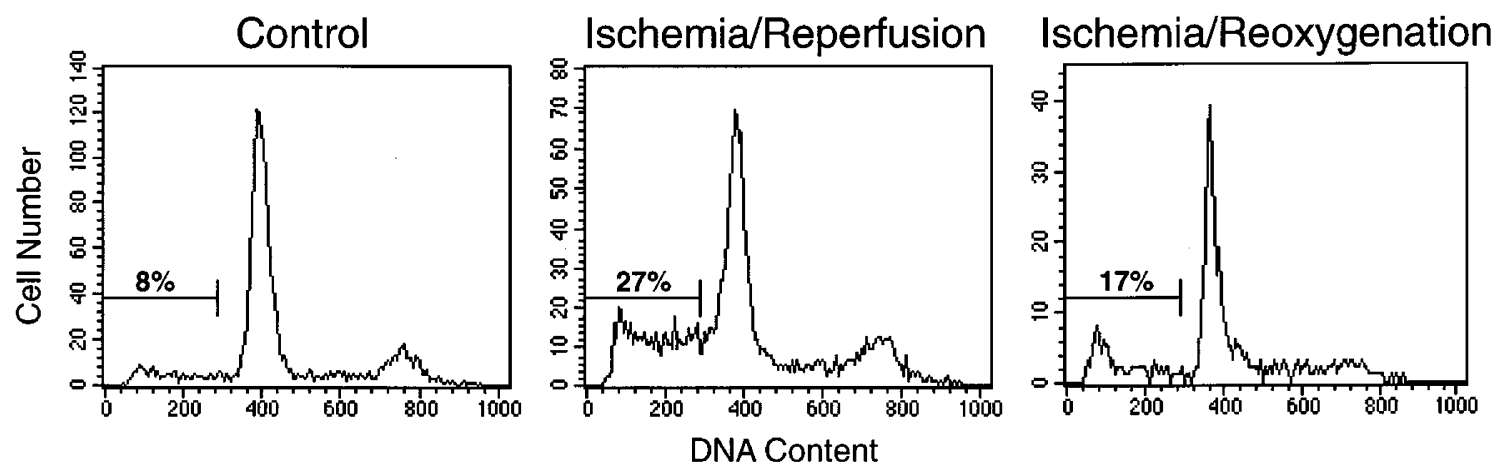

Figure 4 DNA degradation in rat neonatal cardiomyocytes after ischemia with the subsequent reperfusion or reoxygenation. Numbers on DNA histograms indicate per cent of $<2$ C DNA cells. 


\section{Cardiomyocyte death induced by divers pro-apoptotic agents}

Myocardial cell apoptosis has become a subject of study only recently. Little or no data has been published regarding the mechanism of cardiomyocyte death induced by divers cytotoxic stimuli. Using rat neonatal cardiomyocytes, we analyzed the cytotoxic effects of agents shown to have different mechanisms of action (Figure 5). Agents studied were: adriamycin, a chemotherapeutic drug thought to involve topoisomerase II inhibition and to generate reactive oxygen species (Olson and Mushlin, 1990; Duran et al, 1966), staurosporine, a nonspecific protein kinase inhibitor capable of inducing apoptotic cell death in many systems (Tamaoki et al, 1986); cis-platinum, believed to produce DNA - DNA and DNA-protein crosslinking (Zamble and Lippard, 1995); puromycin and cycloheximide, protein synthesis inhibitors, and menadione which leads to generation of reactive oxygen species (Thor et al, 1982). Adriamycin has been of special interest because it is known to produce severe cardiotoxicity in humans (Olson and Mushlin, 1990). All these compounds have been found to be toxic for cardiomyocytes (Figure 5) in dose ranges similar to those in other cell systems, and to induce the morphological changes of nuclei characteristic of apoptosis (Figure $2 \mathrm{C}-\mathrm{G}$ ). With the exception of menadione, all agents tested also induce internucleosomal DNA fragmentation (Figure 3, lanes $4-8$ ). It is interesting that in the same cell type some agents induce DNA fragmentation and chromatin condensation and menadione induces only the latter. That means that, as in some other systems (Tomei et al, 1993; Cohen et al, 1992), in cardiomyocytes chromatin condensation is not dependent on the internucleosomal DNA cleavage.

\section{Effect of SFL and ROM on cardiomyocyte death induced by different agents}

The ability to protect $\mathrm{C} 3 \mathrm{H} 10 \mathrm{~T} 1 / 2$ cells from serum deprivation induced apoptosis has been used as a criterion for the purification of SFL. Therefore, we started the investigation of the effect of SFL and ROM on cardiomyocyte death by using a serum deprivation assay. Both SFL and ROM inhibited the death of rat neonatal cardiomyocytes induced by serum and serum/glucose deprivation (Figure $6 \mathrm{~A}$ and $\mathrm{B}$ ). Protection has been evaluated by measurement of the amount of adherent cells (Figure 6), by analysis of cell morphology (Figure 7) and by inhibition of internucleosomal DNA fragmentation (Figure 8 , lanes 2 and 3). Because of the similar effect of SFL and

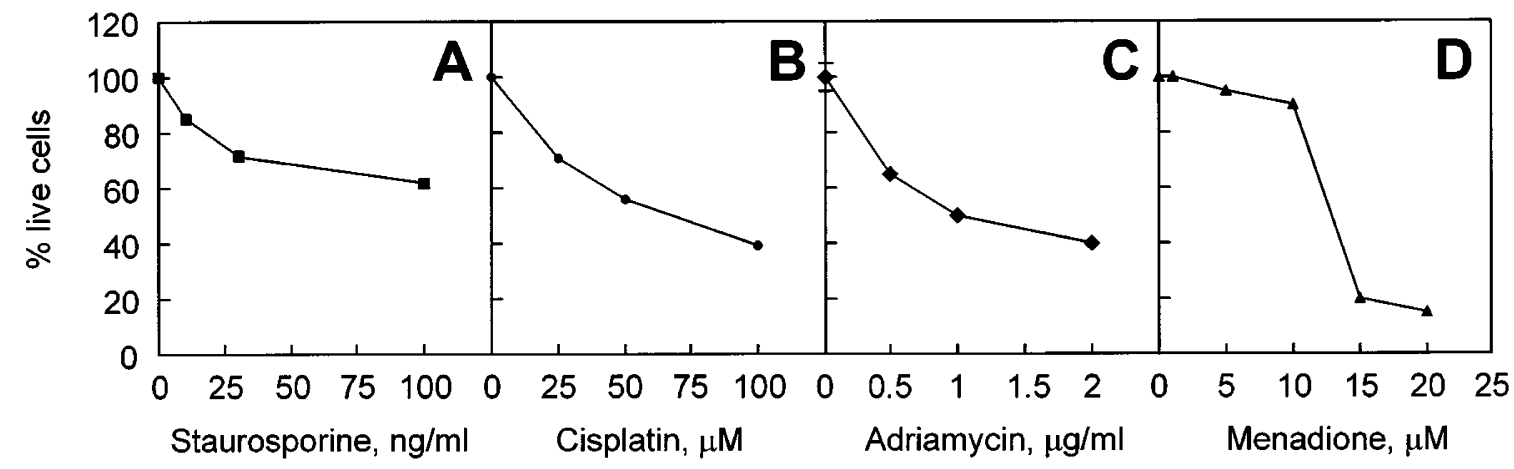

Figure 5 Cardiomyocyte death induced by different cytotoxic agents. Cardiomyocytes were treated with different agents at concentrations indicated, and $24 \mathrm{~h}$ later cell death was measured by the decrease in the amount of adherent cells as described in Materials and methods.
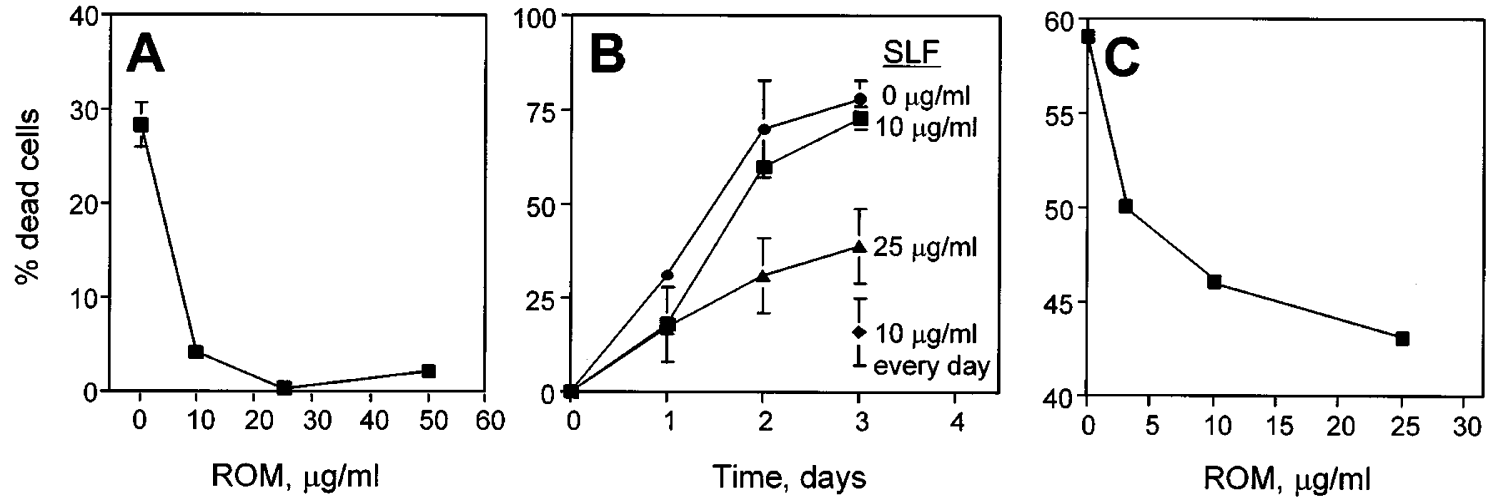

Figure 6 Prevention of cardiomyocyte death by SLF or ROM. (A) $24 \mathrm{~h}$ serum deprivation in the absence or presence of ROM; (B) kinetics of cell death in a serum and glucose free medium. SLF was added once at the beginning of experiments $(0,10$ or $25 \mu \mathrm{g} / \mathrm{ml})$ or each $24 \mathrm{~h}(10 \mu \mathrm{g} / \mathrm{ml})$. (C) after $8 \mathrm{~h}$ ischemia glucose and ROM were added and the cultures were returned to a normal oxygen gas overlay for $16 \mathrm{~h}$ 

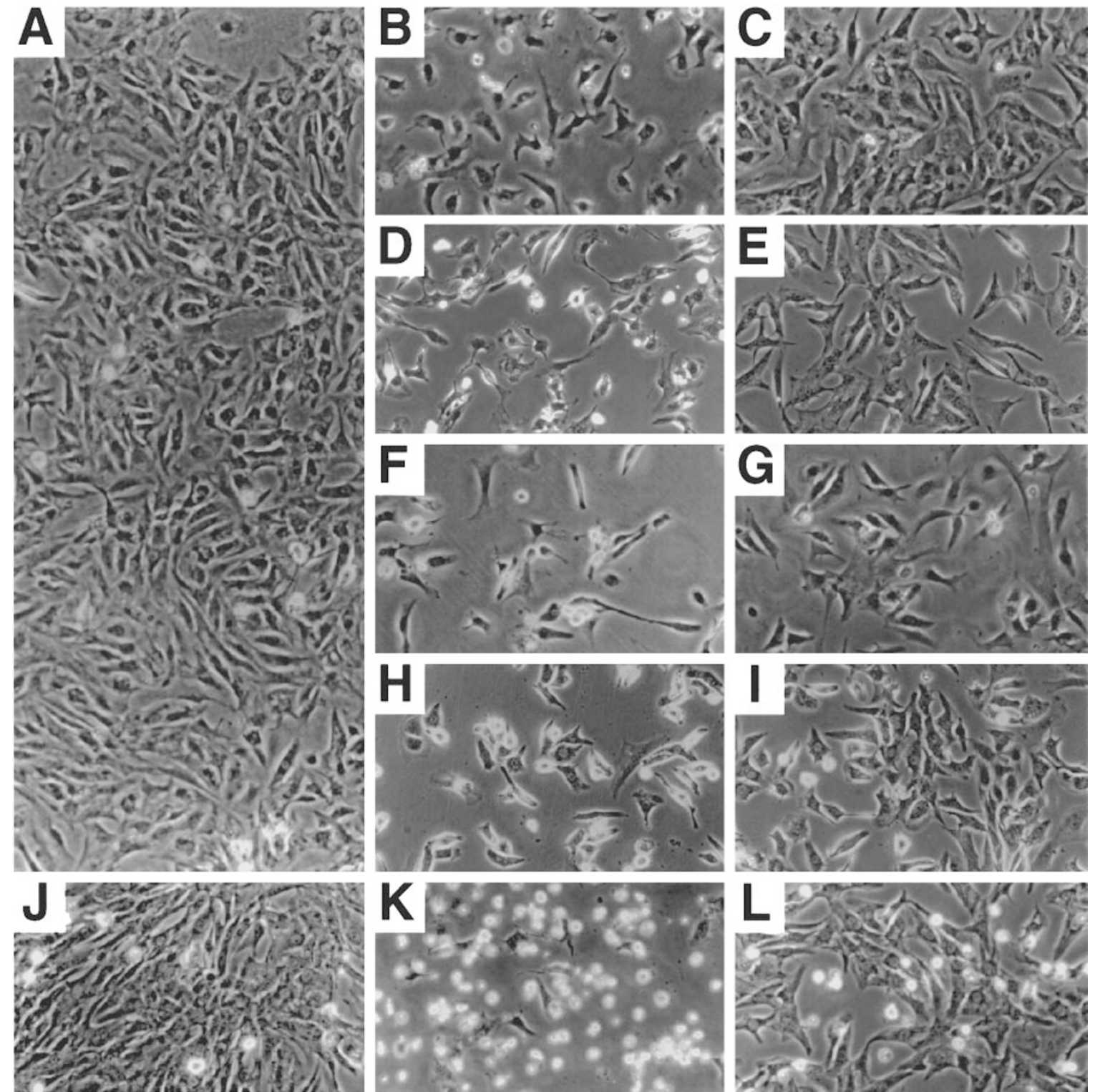

Figure 7 Light microscopy of rat neonatal cardiomyocytes after different treatments in the absence or presence of ROM or SLF. (A-I) and (J-L) 24 and $72 \mathrm{~h}$ incubation respectively. (A) and (J) controls; (B) and (C) serum deprivation; (D,E,K) and (L) serum and glucose deprivation; (F) and (G) ischemia and reperfusion; (H) and (I) cells were treated with $10 \mu \mathrm{mol}$ C2-ceramide. (B,D,F,H) and (K) no additions; (C,E,G) and (I) $10 \mu \mathrm{g} / \mathrm{ml}$ of ROM were added at the beginning of the experiment; (L) $10 \mu \mathrm{g} / \mathrm{ml} \mathrm{SLF}$ were added each day.

ROM in this and other systems, we continued to use ROM mainly in following studies.

As will be explained below, experiments with ROM required simulated reperfusion to be provided in the presence of oxygen and glucose, but in the absence of serum. Figure $6 \mathrm{C}$ and $7 \mathrm{~F}, \mathrm{G}$ shows the dose dependent protection of cardiomyocytes by ROM added after ischemia. $25 \mu \mathrm{g}$ ROM per $\mathrm{ml}$ causes about $25 \%$ reduction in the amount of dead cells. Taking into account the permeability data (Umansky et al, 1995) that shows that about $20-30 \%$ of cells die during $8 \mathrm{~h}$ ischemia, ROM prevents the death of $40-50 \%$ of the cardiomyocytes which die during simulated reperfusion. We found that by varying the time of ischemia, we could modify the amount of cardiomyocytes that die by the end of reperfusion and the proportion of cells which die during ischemia and reperfusion. As ischemia was shortened, the amount of cells dying by the beginning of simulated reperfusion was lessened and the portion of cells which die during reperfusion became greater. If, in the absence of ROM, the amount of dead cells was $60 \%, 49 \%$ and $38 \%$, the amount of dead cells decreased by $26.7 \%, 40.8 \%$ and $50 \%$, respectively, with the addition of $5 \mu \mathrm{g}$ ROM. Thus, in agreement with our predictions, protection with ROM added after ischemia was more pronounced when the total amount of dead cells without ROM was lower. Addition of ROM before ischemia is not more protective than ROM treatment during simulated reperfusion only. Thus, ROM does not decrease damage induced by ischemia and does not prevent the 


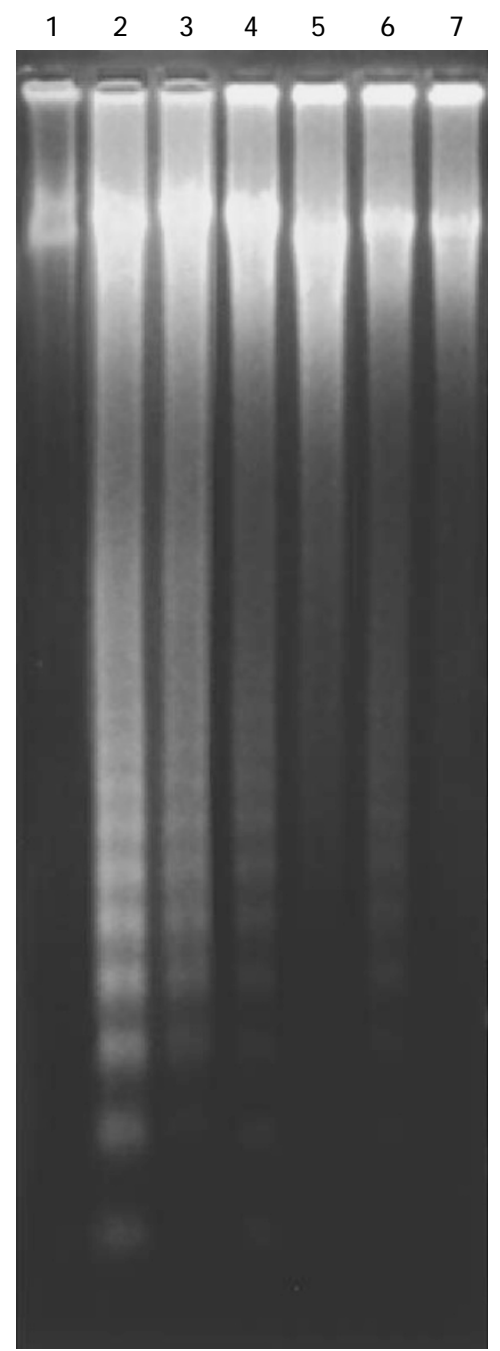

Figure 8 Agarose gel electrophoresis of DNA isolated from rat neonatal cardiomyocytes after different treatments in the absence or presence of $10 \mu \mathrm{g} /$ $\mathrm{ml}$ of ROM. (1) control; (2 and $\mathbf{3}$ ) serum and glucose deprivation in the absence and presence of ROM, respectively; (4 and 5) $10 \mu \mathrm{mol} \mathrm{C2-ceramide} \mathrm{in} \mathrm{the}$ absence and presence of ROM, respectively; ( 6 and 7$) 7.5 \mu \mathrm{mol}$ C2-ceramide in the absence and presence of ROM, respectively. necrotic cell death that occurs before the beginning of reperfusion. Taken together, these data demonstrate the ability of SLF and ROM to prevent the apoptotic death of cardiomyocytes induced by serum or serum/glucose deprivation and by simulated ischemia/reperfusion.

To investigate whether ROM possesses anti-apoptotic activity against other cytotoxic treatments it was added to cardiomyocytes together with cycloheximide, puromycin, adriamycin, staurosporine, cis-platinum, or menadione. In all these cases we could not find a significant decrease in the amount of dead cells (data not shown).

\section{ROM blocks the apoptotic pathway initiated by ceramide}

Despite of the similarity of the final stages of apoptosis induced by different agents initial signaling mechanisms depend upon the nature of physiological or damaging cytotoxic stimuli and are not well understood. During the last few years, the involvement of ceramide, a lipid secondary messenger generated from sphingomyelin by acidic and neutral sphingomyelinases, in triggering apoptosis has been intensively investigated (Hannun and Obeid, 1995; Kolesnick and Fuks, 1995). Ceramide is involved as a secondary messenger in the transduction of pro-apoptotic signal from the TNF-receptor and CD95 (Fas/APO-1) (Dbaibo et al, 1993; Cifone et al, 1993; Kolesnick and Golde, 1994; Tepper et al, 1995), as well as in the induction of apoptosis by $\gamma$-irradiation (Haimovitz-Friedman et al, 1994), serum deprivation (Esteve et al, 1995; Jayadev et al, 1995) and antibiotic daunorubicin (Bose et al, 1995). Soluble synthetic ceramides are also capable of inducing apoptotic death in different cell types (Obeid et al, 1993).

Figure 9A shows that synthetic C2-ceramide kills rat neonatal cardiomyocytes in a dose dependent manner. Cell morphology (Figure $2 \mathrm{H}$ ), accumulation of cells containing less than 2C DNA (data not shown) and internucleosomal DNA fragmentation (Figure 3, lane 2) demonstrate that the cells are dying by apoptosis.

ROM effectively prevents ceramide-induced cardiomyocyte death (Figure $7 \mathrm{H}, \mathrm{I}, 11 \mathrm{~B}$ ) and internucleosomal DNA
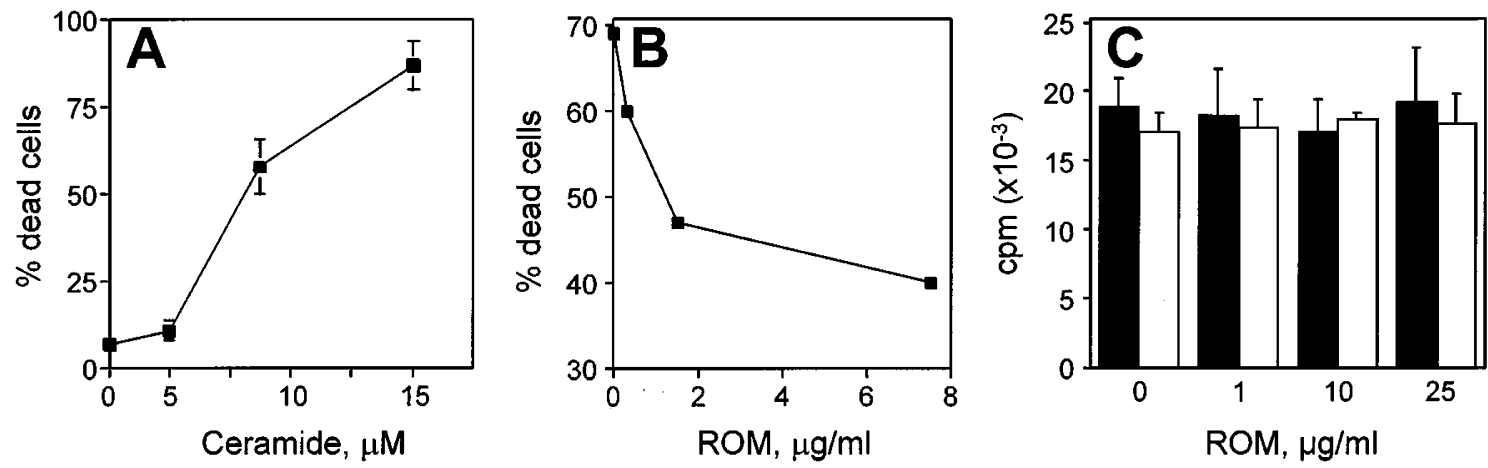

Figure 9 Ceramide-induced death of cardiomyocytes and its prevention by ROM. (A) dose dependence of C2-ceramide-induced cardiomyocyte death; (B) cells were treated with $15 \mu \mathrm{mol}$ ceramide in the presence of the indicated amounts of ROM. (C) $10 \mu \mathrm{mol}\left[{ }^{3} \mathrm{H}\right] \mathrm{C} 2$-ceramide (a kind gift of Dr Alicja Bielawska) and different amounts of ROM were added to cardiomyocytes in RPMI. After $1 \mathrm{~h}$ (black bars) or $3 \mathrm{~h}$ (white bars) incubation cells were washed five times with RPMI, trypsinized, collected onto filters and their radioactivity was measured. 
degradation (Figure 8, lanes 4-7). Since ROM is a mixture of phospholipids and forms micelles in water solutions, one can suggest that ceramide is sequestered in these complexes, thus preventing the interaction of ceramide with cardiomyocytes. To check this possibility, we incubated cardiomyocytes with ${ }^{3} \mathrm{H}$-labeled ceramide in the presence of increasing concentrations of ROM and measured the amount of ceramide bound to cells after 1 and $3 \mathrm{~h}$ (Figure $9 \mathrm{C}$ ). In the absence of ROM, cadiomyocytes bound about $25-30 \%$ of added ceramide. ROM had no effect on ceramide binding even at doses much higher than ones which protect cardiomyoctes from ceramide toxicity.

\section{Discussion}

Now it is well established that ischemia and reperfusion cause necrotic and apoptotic death of cardiomyocytes both in vitro and in vivo (Gottlieb et al, 1994; Ito et al, 1995; Umansky et al, 1995, 1996). Data presented show that other cytotoxic agents with different mechanisms of action also induce apoptosis in myocardial cells. Particularly, this result is important to interpret the effect of adriamycin on cardiac cells since its use as a chemotherapeutic agent is limited by its cardiotoxicity. The understanding of the mechanisms of cardiomyocyte death is not a purely theoretical problem. As we have discussed above, the approaches for the modification of necrotic and apoptotic cell death are different. To inhibit necrotic death we can only prevent the cell injury and early reperfusion and the use of antioxidants are the part of this therapeutic strategy. However, apoptosis can be also prevented by the interfering with signaling mechanisms and the apoptotic pathway.

In this study we employed this approach to prevent cardiomyocyte death by using a new anti-apoptotic compound originally purified from soy flour on the basis of its anti-apoptotic activity. Both the preparation obtained from flour and the reconstructed mixture with optimized ratio of five phospholipids were used and quite similar results have been obtained. SLF and ROM inhibit cardiomyocyte death induced by serum and serum/glucose deprivation, and partially prevent simulated ischemia/ reperfusion-induced death of cardiomyocytes but they have no effect on apoptosis induced by inhibitors of protein synthesis, adriamycin, menadione, cis-platinum, and staurosporine.

Apoptosis can be triggered by different mechanism, and the initial stages of apoptosis can vary depending on the nature of the pro-apoptotic signal. Recently, ceramide was found to be a secondary messenger in apoptosis induced by signaling through the TNF-receptor (Dbaibo et al, 1993; Kolesnick and Golde, 1994) and CD95 (Fas/APO-1) (Cifone et al, 1993; Tepper et al, 1995), by irradiation (HaimovitzFriedman et al, 1994), serum deprivation (Esteve et al, 1995; Jayadev et al, 1995) and some other treatments. Accumulation of ceramide is usually a result of sphingomyelinase activation which leads to hydrolysis of sphingomyelin into ceramide and phosphocholine but the induction of ceramide synthesis de novo has also been observed (Bose et al, 1995). Triggering of apoptosis by ceramide occurs through activation of protein kinase cascade including a stress-activated protein kinase (Westwick et al, 1995; Verheji et al, 1996). Some data indicate that ceramide-mediated and p53-mediated apoptosis are distinct and independent.

Data presented above show that the addition of ceramide induces apoptotic death in rat neonatal cardiomyocytes and, thus, all components necessary for ceramide-mediated apoptosis are present in cardiomyocytes. Ceramide measurement is necessary to find out which pro-apoptotic stimuli induce cardiomyocyte death through this ceramide-mediated pathway. However, the data on prevention of ceramide-induced apoptosis by ROM suggest that ceramide may also be involved in triggering cardiomyocyte death induced by serum or serum/glucose deprivation and by ischemia/reperfusion which also is inhibited by ROM. The possible mechanisms of ROM interference with ceramide-mediated apoptosis are not clear. One of the active components of ROM is LPA. LPA alone can partially protect cardiomyocyte from apoptosis induced by serum deprivation (data not shown). Unfortunately, the solubility of LPA in water solutions is very low and LPA is easily adsorbed to glass, plastic and other surfaces, and rapidly disappears from solution. The combination of several phospholipids in ROM leads to formation of stable micelles and keeps LPA in the medium. It is known that during blood coagulation LPA is liberated from platelets and binds to albumin (Moolenar, 1995). Thus, any serum contains LPA adsorbed to albumin (Tigyi and Miledi, 1992). Therefore all experiments with ROM were performed in the absence of serum. LPA effects on cell growth and differentiation have been described (Moolenar, 1995) and our data indicate the possible involvement of LPA in the regulation of apoptosis. It is known that LPA can transduce a signal from the cell surface through a LPA-receptor and the putative receptor has been purified recently (Guo et al, 1996). Among other intracellular events induced by LPA is the increase of DAG concentration (Moolenar, 1995) and DAG has been shown to be an inhibitor of ceramideinduced apoptosis (Jarvis et al, 1994). Of course any suggestion as to the mechanisms of ROM or LPA antiapoptotic activity is now speculative but it indicates the potential approaches for future studies.

Thus, the data presented here demonstrate the important role of apoptosis in myocardial cell injury induced by different agents. A mixture of phospholipids possessing the anti-apoptotic activity in different systems is also effective in the prevention of cardiomyocyte apoptosis induced by serum deprivation, simulated in vitro ischemia/ reperfusion and ceramide. The latter finding indicates a possible involvement of ceramide in triggering ischemia/ reperfusion induced apoptosis of cardiomyocytes. Recently we have shown that ischemia/reperfusion induced an increase of the ceramide levels both in vitro and in vivo (Bielawska et al, manuscript in preparation).

The data presented in this paper demonstrate the efficacy of a new approach in the treatment of the consequences of ischemia, based on interference with the apoptotic pathway. 


\section{Materials and methods}

\section{Isolation of rat neonatal cardiomyocytes}

Cardiomyocytes were prepared from hearts of day-old Sprague Dawley rats by trypsinization and mechanical disaggregation (Simpson, 1985). The cells were resuspended in MEM, $1 \times$ MEM vitamins (Gibco), $5 \%$ fetal bovine serum and $50 \mathrm{U} / \mathrm{ml}$ penicillin-G and pre-plated for $30 \mathrm{~min}$ to reduce contamination of non-myocytes. The non-adherent cardiac myocytes were separated and seeded in $2 \mathrm{ml}$ in $35 \mathrm{~mm}$ dishes at a density of $3.5 \times 10^{5}$ viable cells per $\mathrm{ml}$. The cells were allowed to adhere for $16-24 \mathrm{~h}$ in a $37^{\circ} \mathrm{C} / 5 \% \mathrm{CO}_{2}$ humidified incubator.

\section{Cardiomyocyte treatment}

Following the initial incubation period, each culture plate was washed with fresh medium prior to addition of RPMI $/ 10 \%$ fetal bovine serum containing either adriamycin, menadione, staurosporine or cisplatinum. The cultures were then incubated for $24 \mathrm{~h}$.

For serum deprivation, the medium was replaced with fresh serumfree RPMI, whereas serum/glucose deprivation was performed using glucose-free RPMI. The induction of cell death by $\mathrm{C}_{2}$-ceramide was accomplished by the addition of the agent prepared in serum-free RPMI. As a model of ischemia, cultures in serum and glucose free RPMI were placed in an airtight chamber and the latter was continuously perfused with oxygen-free gas overlay of $95 \% \mathrm{~N}_{2} / 5 \%$ $\mathrm{CO}_{2}$ for $8 \mathrm{~h}$ at $37^{\circ} \mathrm{C}$. To model reperfusion of the ischemic cells, $10 \%$ fetal bovine serum, $2 \mathrm{~g} / \mathrm{L}$ of glucose were added and the cultures were returned to a normal oxygen gas overlay $\left(37^{\circ} \mathrm{C} / 5 \% \quad \mathrm{CO}_{2}\right)$ in a humidified incubator for $16 \mathrm{~h}$.

\section{Purification of SFL}

Purification of the anti-apoptotic factor from soy flour was performed using the 10T1/2 apoptotic cell assay to monitor the anti-apoptotic activity. (Tomei et al, 1993). Soy flour, type 1 (Sigma, St Louis, MO) was defatted with $70 \%$ acetone and extracted with $50 \%$ ethanol. The extract was concentrated 100 times by ultrafiltration through $10 \mathrm{kDa}$ membrane (Filtron, Boston, MA) and lyophilized. The powder was extracted with the mixture water: methanol: chloroform $(3: 8: 4)$. The soluble fraction containing the majority of the anti-apoptotic activity was reclaimed by rotary evaporation and lyophilized.

For these experiments, SFL or ROM were prepared by sonication at the concentration $10 \mathrm{mg} / \mathrm{ml}$ in $105 \mathrm{mmol} \mathrm{NaCl} / 50 \mathrm{mmol}$ ammonium bicarbonate, $\mathrm{pH} 8.0$ and added to cells in serum free medium at the concentrations indicated.

\section{Measurement of cell death}

Since cardiomyocytes are differentiated non-dividing cells, viability was determined by measurement of the decrease in the relative number of adherent cells. The measurement of non-adherent cells was found to be less reproducible because of their rapid lysis following release from adhesion substrate. Adherent cardiomyocytes were collected from culture dishes using $0.25 \%$ Trypsin $/ 0.05 \%$ EDTA and counted on Coulter Counter ZM and Coulter Channelyzer 256.

\section{Analysis of DNA degradation}

For flow cytometry analysis, adherent and non-adherent cells were combined. Cells were fixed in $50 \%$ ethanol, treated $30 \mathrm{~min}$ with
$100 \mu \mathrm{g} / \mathrm{ml} \mathrm{RNase}$, stained with $40 \mu \mathrm{g} / \mathrm{ml}$ propidium iodide and the amount of cells containing $<2 \mathrm{C}$ DNA was registered by FACScan. DNA was isolated from combined adherent and non-aherent cells and analyzed by agarose gel electrophoresis. $10 \mu \mathrm{g}$ DNA were loaded on each lane.

Each experiment was repeated 6-8 times and typical data are presented.

\section{Acknowledgements}

The authors wish to acknowledge the assistance with the manuscript preparation by Eugene Shekhtman and Virginia Powers.

\section{References}

Afanasyev VN, Korol' BA, Mantsygin YA, Nelipovich PA and Umansky SR (1986) Flow cytometry and biochemical analysis of DNA degradation characteristic of two types of cell death. FEBS Letters 194: 347-350

Afanasyev VN, Korol' BA, Matylevich NP, Pechatnikov VA and Umansky SR (1993) The use of flow cytometry for the investigation of cell death. Cytometry 14:603609

Bose R, Verheij M, Haimovitz-Friedman A, Scotto K, Fuks Z and Kolesnick R (1995) Ceramide synthase mediates daunorubicin-induced apoptosis: an alternative mechanism for generating death signals. Cell 82: 1-20

Buerke M, Murohara T, Skurk C, Nuss C, Tomaselli K and Lefer AM (1995) Cardioprotective effect of insulin-like growth factor I in myocardial ischemia followed by reperfusion. Proc Natl Acad Sci USA 92: 8031-8035

Cifone MG, De Maria R, Roncaioli P, Rippo MR, Azuma M, Lanier LL, Santoni A and Testi R (1993) Apoptotic signaling through CD95 (Fas/Apo-1) activates an acidic sphingomyelinase. J Exp Med. 177: 1547-1552

Cohen GM, Sun XM, Snowden RT, Dinsdale D and Skiletter DN (1992) Key morphological features of apoptosis may occur in the absence of internucleosomal DNA fragmentation. Biochem J. 286: 331-334

Dbaibo GS, Obeid LM and Hannun YA (1993) Tumor necrosis factor- $\alpha$ (TNF- $\alpha$ ) signal transduction through ceramide. J Biol Chem. 268: 17762-17766

Duran GE, Lau DH, Lewis AD, Kuhl JS, Bammler TK and Sikic BI (1966) Differential single-versus double-strand DNA breakage produced by doxorubicin and its morpholinyl analogues. Cancer Chemother Pharmacol. 38: 210-216

Esteve P, del Peso L and Lacal JC (1995) Induction of apoptosis by rho in NIH3T3 cells requires two complementary signals. Ceramides function as a progression factor for apoptosis. Oncogene. 11: 2657-2665

Fox KAA (1992) Reperfusion injury: laboratory phenomenon or clinical reality? Cardiovasc Res. 26: 656-659

Gottlieb RA, Burleson KO, Kloner RA, Babior BM and Engler RL (1994) Reperfusion injury induces apoptosis in rabbit cardiomyocytes. J Clin Invest. 94: 1621 - 1628

Guo Z, Liliom K, Fischer DJ, Bathurst IC, Tomei LD, Kiefer MC and Tigyi G (1996) Molecular cloning of a high-affinity receptor for the growth factor-like lipid mediator lyphosphatidic acid from Xenopus oocytes. Proc Natl Acad Sci USA. 93: $14367-14372$

Haimovitz-Friedman A, Kan CC, Ehleiter D, Persaud RS, McLouglin M, Fuks Z and Kolesnick RN (1994) lonizing radiation acts on cellular membranes to generate ceramide and initiate apoptosis. J Exp Med. 180: 525-535

Hannun YA and Obeid LM (1995) Ceramide: an intracellular signal for apoptosis. Trends Biochem Sci. 20:73-77

Itoh G, Tamura J, Suzuki M, Suzuki Y, Ikeda H, Koike M, Nomura M, Jie T and Ito K (1995) DNA fragmentation of human infarcted myocardial cells demonstrated by the nick end labeling method and DNA agarose gel electrophoresis. Am J Pathol. 146: $1325-1331$

Jarvis WD, Fornari FA Jr, Browning JL, Gewirtz DA, Kolesnick RN and Grant S (1994) Attenuation of ceramide-induced apoptosis by diglyceride in human myeloid leukemia cells. J Biol Chem. 269: 31685-31692

Jayadev S, Liu B, Bielawska EA, Lee JY, Nazaire F, Pushkareva MY, Obeid LM and Hannun YA (1995) Role for ceramide in cell cycle arrest. JBiol Chem. 270: 20472052

Karmazyn M (1991) Ischemic and reperfusion injury in the heart. Cellular mechanisms and pharmacological interventions. Can J Physiol Pharmacol. 69: $719-730$ 
Kerr JF, Wyllie AH and Currie AR (1972) Apoptosis: A basic biological phenomenon with wide-ranging implications in tissue kinetics. Br J Cancer 26: 239-257

Kolesnick R and Fuks Z (1995) Ceramide: a signal for apoptosis or mitogenesis? Exp Med. 181: 1949-1952

Kolesnick R and Golde DW (1994) The sphingomyelin pathway in tumor necrosis factor and interleukin-1 signaling. Cell 77: 325-328

Moolenaar WH (1995) Lysophosphatidic acid, a multifunctional phospholipid messenger. J Biol Chem. 270: 12949-12952

Nunez G, Merino R, Grillot D and Gonzalez-Garcia (1994) Bcl-2 and Bcl-x: regulatory switches for lymphoid death and survival. Immunol Today 15: 582-588

Obeid LM, Linardic CM, Karolak LA and Hannun Y (1993) Programmed cell death induced by ceramide. Science 259: 1769-1771

Olson RD and Mushlin PS (1990) Doxorubicin cardiotoxicity: analysis of prevailing hypotheses. FASEB J. 4: 3076-3086

Simpson P (1985) Stimulation of hypertrophy of cultured neonatal rat heart cells through an $\alpha_{1}$-adrenergic receptor and induction of beating through an $\alpha_{1}$-and $\beta_{1}$-adrenergic receptor interaction: evidence for independent regulation of growth and beating. Circulation Res. 56: 884-894

Tamaoki T, Nomoto H, Takahashi I, Kato Y, Morimoto M and Tomita F (1986) Staurosporine, a potent inhibitor of phospholipid/ $\mathrm{Ca}^{++}$dependent protein kinase. Biochem Biophys Res Comm. 135: 397-402

Tepper CG, Jayadev S, Liu B, Bielawska A, Wolff R, Yonehara S, Hannun YA and Seldin MF (1995) Role of ceramide as an endogenous mediator of Fas-induced cytotoxicity. Proc Natl Acad Sci USA. 92: 8443-8447

Thor H, Smith MT, Hartzell P, Bellomo G, Jewell SA and Orrenius S (1982) The metabolism of menadione (2-methyl-1,4-naphtoquinone) by isolated hepatocytes. J Biol Chem. 257: 12419-12425
Tigyi G and Miledi R (1992) Lysophosphatidates bound to serum albumin activate membrane currents in Xenopus oocytes and neurite retraction in $\mathrm{PC} 12$ pheochromocytoma cells. J Biol Chem. 267: 21360-21367

Tomei LD, Shapiro JP and Cope FO (1993) Apoptosis in C3H/10T1/2 mouse embryonic cells: evidence for internucleosomal DNA modification in the absence of double-strand cleavage. Proc Natl Acad Sci USA. 90: 853-857

Umansky S (1996) Apoptosis: molecular and cellular mechanisms (a review). Molecular Biology 30: 285-295

Umansky SR, Cuenco GM, Khutzian SS, BarrPJ and Tomei LD (1995) Post-ischemic apoptotic death of a rat neonatal cardiomyocytes. Cell Death Differ. 2: 235-241

Umansky SR, Pisarenko OI, Serebryakova LI, Studneva IM, Tskitishvili OV, Khutsian SS, Sukhova TI, Lichtenstein AV, Ossina NK, Kiefer MC and Tomei LD (1996) Dog cardiomyocyte death induced in vivo by ischemia and reperfusion. Basic and Applied Myology. 6: 227-235

Vaux DL and Strasser A (1996) The molecular biology of apoptosis. Proc Natl Acad Sci USA. 93: 2239-2244

Verheij M, Bose R, Lin XH, Yao B, Jarvis WD, Grant S, Birrer MJ, Szabo E, Zon LI, Kyriakis JM, Haimovitz-Friedman A, Fuks Z and Kolesnick RN (1996) Requirement for ceramide-initiated SAPK/JNK signalling in stress-induced apoptosis. Nature 380: 75-79

WestwickJK, Bielawska AE, Dbaibo G, Hannun YAandBrennerDA (1995)Ceramide activates the stress-activated protein kinases. J Biol Chem. 270: 22689-22692

Whyte M (1996) ICE/CED-3 proteases in apoptosis. Trends in Cell Biol. 6: 245-248

Zamble DB and Lippard SJ (1995) Cisplatin and DNA repair in cancer chemotherapy. Trends Biochem Sci. 20: 435-439 